\title{
Capacity of Primary Care to Deliver Telehealth in the United States
}

\author{
Anuradha Jetty, MPH, Yalda Jabbarpour, MD, Matthew Westfall, BA, \\ Douglas B. Kamerow, MD, MPH, Stephen Petterson, PhD, and John M. Westfall, MD, MPH
}

Background: Because of the Coronavirus disease 2019 (COVID 19) pandemic, many primary care practices have transitioned to telehealth visits to keep patients at home and decrease the transmission of the disease. Yet, little is known about the nationwide capacity for delivering primary care services via telehealth.

Methods: Using the 2016 National Ambulatory Medical Survey we estimated the number and proportion of reported visits and services that could be provided via telehealth. We also performed cross-tabulations to calculate the number and proportion of physicians providing telephone visits and e-mail/ internet encounters.

Results: Of the total visits (nearly 400 million) to primary care physicians, $42 \%$ were amenable to telehealth and $73 \%$ of the total services rendered could be delivered through telehealth modalities. Of the primary care physicians, $44 \%$ provided telephone consults and $19 \%$ provided e-consults.

Discussion: This study underscores how and where primary care services could be delivered. It provides the first estimates of the capacity of primary care to provide telehealth services for COVID-19 related illness, and for several other acute and chronic medical conditions. It also highlights the fact that, as of 2016, most outpatient telehealth visits were done via telephone.

Conclusions: This study provides an estimate of the primary care capacity to deliver telehealth and can guide practices and payers as care delivery models change in a post-COVID 19 environment. ( $\mathrm{J}$ Am Board Fam Med 2021;34:S48-S54.)

Keywords: Child Health, COVID-19, Family Medicine, Mental Health, Pandemics, Primary Care Physicians, Primary Health Care, Rural Health, Social Determinants of Health, Telemedicine

\section{Background}

The Coronavirus disease 2019 (COVID 19) pandemic has rapidly and dramatically changed the delivery of primary care in the short term, shifting many visits from traditional face-to-face encounters to telehealth only encounters. This shift has many

This article was externally peer reviewed.

Submitted 07 May 2020; revised 23 July 2020; accepted 26 July 2020.

From The Robert Graham Center for Policy Studies in Primary Care, Washington, DC (AJ, YJ, DBK, SP, JW); Virginia Commonwealth University School of Medicine, Richmond, VA (MW).

Funding: No funding received for this study.

Conflict of interest: We have no conflicts of interest to disclose.

Author contributions: All authors collectively and independently are responsible for the content and made substantial contributions to this paper. Specifically, Anuradha Jetty, Yalda Jabbarpour, and John Westfall designed and developed the study concept. Matthew Westfall conducted the literature review and helped in drafting the introduction section. Douglas Kamerow, John Westfall, Yalda Jabbarpour and clinicians, payers and policy makers questioning the feasibility of telehealth long-term. Despite limited incorporation before March 2020, a number of essential primary care services may be delivered by the spectrum of telehealth modalities. ${ }^{1}$ For instance, many studies indicate the feasibility of using telehealth modalities to provide examinations and screenings, mental and behavioral health counseling, health education, and preventive care. $^{2-6}$ Other studies suggest some primary care services

Anuradha Jetty examined all the services available in the NAMCS data and classified them into telehealth amenable and non-telehealth amenable. Anuradha Jetty analyzed the data, interpreted results, and drafted the results and methods sections. Yalda Jabbarpour drafted the discussion section and concluding remarks. Stephen Petterson interpreted the results, reviewed the manuscript for intellectual and critical content. Douglas Kamerow and John Westfall reviewed the manuscript for intellectual and critical content.

Corresponding author: Anuradha Jetty, MPH, 1133 Connecticut Ave NW, Suite 1100, Washington DC 20036 (E-mail: ajetty@aafp.org). 
may be effectively provided via telehealth. ${ }^{7-10} \mathrm{~A}$ limited number of studies indicate telehealth may be comparatively effective vs traditional face-toface care and may also save money. ${ }^{11-17}$

The slow uptake of telehealth before the COVID-19 pandemic had many causes, from poor reimbursement to lack of infrastructure to burdensome rules and regulations to patient and provider preferences. The need to slow the spread of COVID-19 and keep patients at home has resulted in rapid changes in care delivery followed by significant changes in payment and regulation that have supported a rapid transition to telehealth. ${ }^{18}$

Despite current transitions to telehealth-based practice and evidence that many primary care services may be effectively delivered via telehealth, little is known about the nationwide capacity for delivering primary care services via telehealth. The purpose of this study was to analyze the primary care capacity to deliver services and clinical care through telehealth mechanisms. We explored this topic using the National Ambulatory Medical Survey 2016 (NAMCS) data.

We used 2 approaches to explore telehealth: (1) a broader definition of telehealth visit that includes patient-physician encounters that are telephone or internet/e-mail consults, and (2) a visit where provision of at least 1 service requires physical presence of a physician was defined as not amenable to telehealth. All those visits that did not require physical presence of a physician were termed as amenable to telehealth.

\section{Study Data and Methods \\ Data Sources}

NAMCS is an annual survey administered by the Division of Health Statistics, National Center for Health Statistics. Data are collected using a national multistage probability sample of visits to non-federally employed physicians. The sampling frame for the NAMCS 2016 was derived from databases maintained by the American Medical Association (AMA) or the American Osteopathic Association (AOA) though membership in these organizations is not required for listing. The patient-physician encounter in an office-based setting is the primary sampling unit. Each physician is assigned a 1-week reporting period; the physician reports data on all the ambulatory care visits that may have occurred during that period. We used the 2016 NAMCS data to explore the telehealth capacity of primary care physicians. The response rate was $39.3 \%$ for physicians who provided data for at least 1 encounter.

The main data collection includes computerassisted automated tools accessible through the Web portal or a laptop computer provided by the data collection staff. Two forms, the Patient Record Form and the Physician Induction Interview Form, are used to record the data. The Physician Induction Interview Form is used to collect information about the characteristics of the physician practices. The Patient Record Forms are used to measure data on socio-demographic characteristics, expected source of payment, the reason for visit, diagnosis for the current visit, continuity of care information, existing chronic conditions, diagnostic and screening tests ordered or provided in the office, procedures, medication therapy, types of providers seen, and provision of preventive health education during the targeted study period. Either the physician or their staff report the data or the Census field representative abstracts the data from the medical charts. The survey methodology including sampling design, data instruments, and data collection procedures are described in detail elsewhere. ${ }^{19}$ All the services provided by the physician were divided into categories: (1) examinations/screening, (2) lab tests, (3) imaging, (4) procedures, (5) treatment, and (6) health education/counseling (complete list of services found at https://www.cdc.gov/nchs/ data/ahcd/2016_namcs_prf_sample_card.pdf). ${ }^{20}$

\section{Methods}

We used 2 approaches to quantify the telehealth capacity of the primary care physicians: (1) examine distribution of e-consults and telephone consults and (2) all the encounters amenable to telehealth in a primary care office-based setting. Primary care specialty included general practice, family practice, internal medicine, and pediatrics.

We used the following question to calculate the proportion of physicians providing the following types of visits *"During the last typical week of practice, did you make encounters of the following types with patients: (1) telephone consults, (2) internet/e-mail encounters with patients, (3) nursing home visits, (4) home visits, and (5) hospital visits. Each of these options was recorded as ' 1 ' if the physician answered "yes," ' 0 ' and if they answered "no." Blank, unknown, and refused answers were set to missing. 
Table 1. Distribution of Patient-Physician Encounters by Patient Characteristics and Telehealth Amenability

\begin{tabular}{|c|c|c|c|c|c|}
\hline \multirow[b]{2}{*}{ Characteristics } & & \multicolumn{3}{|c|}{ Telehealth Amenable } & \multirow{2}{*}{$P$ Value } \\
\hline & & $\mathrm{n}$ & $\begin{array}{c}\text { Yes } \\
\text { (Weighted \%) }\end{array}$ & $\begin{array}{c}\text { No } \\
\text { (Weighted \%) }\end{array}$ & \\
\hline \multirow[t]{6}{*}{ Age, y } & 0 to 17 & 1699 & 39.1 & 61.9 & .02 \\
\hline & 18 to 34 & 1739 & 42.0 & 58.0 & \\
\hline & 35 to 44 & 1154 & 37.1 & 62.9 & \\
\hline & 45 to 54 & 1628 & 33.8 & 66.2 & \\
\hline & 55 to 64 & 2140 & 33.2 & 66.8 & \\
\hline & $65 \mathrm{p}$ & 4320 & 29.8 & 71.2 & \\
\hline \multirow[t]{2}{*}{ Sex } & Male & 5567 & 35.3 & 64.7 & .91 \\
\hline & Female & 7113 & 35.1 & 64.9 & \\
\hline \multirow[t]{4}{*}{ Race/ethnicity } & White, Non-Hispanic & 9231 & 36.7 & 63.3 & .24 \\
\hline & Black, Non-Hispanic & 1142 & 29.8 & 61.2 & \\
\hline & Other, Non-Hispanic & 603 & 30.4 & 69.6 & \\
\hline & Hispanic & 1704 & 33.8 & 66.2 & \\
\hline \multirow[t]{2}{*}{ Insurance coverage } & Private & 10,553 & 35.1 & 64.9 & .56 \\
\hline & Public & 5233 & 33.0 & 67.0 & \\
\hline \multirow[t]{7}{*}{ Chronic conditions } & Asthma & 782 & 30.5 & 69.5 & .064 \\
\hline & Diabetes & 887 & 31.9 & 68.1 & .30 \\
\hline & Hypertension & 3567 & 31.0 & 69.0 & .021 \\
\hline & Hyperlipidemia & 2004 & 35.9 & 64.1 & .77 \\
\hline & Depression & 1100 & 44.9 & 55.1 & $<.001$ \\
\hline & Coronary Artery Disease & 804 & 24.7 & 75.3 & .010 \\
\hline & Number of Chronic Conditions & 2303 & 2.1 & 2.4 & $<.001$ \\
\hline
\end{tabular}

Source: Author's analysis of the 2016 National Survey of Ambulatory Medical Care Survey weighted by patient weight (n = 12,680, equivalent to $850,695,621$ patient-physician encounters).

To determine which services were amenable to delivery through telehealth, we first conducted an environmental scan of peer-reviewed telehealth literature and created a list of services amenable to telehealth. This list was then shared with a group of primary care physicians who either had use telehealth in the past or were currently using videoenabled or telephone only telehealth during the

Table 2. Proportion of Patient-Physician Encounters Amenable to Telehealth

\begin{tabular}{|c|c|c|c|c|}
\hline \multirow[t]{2}{*}{$\begin{array}{l}\text { Telehealth } \\
\text { Amenable } \\
\text { Encounters }\end{array}$} & \multicolumn{2}{|c|}{ All Physicians } & \multicolumn{2}{|c|}{$\underline{\text { Primary Care Physicians }}$} \\
\hline & $\mathrm{n}$ & $\%$ & $\mathrm{n}$ & $\%$ \\
\hline Yes & $299,347,453$ & 35 & $165,333,984$ & 42 \\
\hline No & $551,348,168$ & 65 & $228,884,017$ & 58 \\
\hline Total & $850,695,621$ & 100 & $394,218,001$ & 100 \\
\hline
\end{tabular}

Source: Author's Analysis of the 2016 National Survey of Ambulatory Medical Care Survey weighted by patient weight.

*Telehealth amenable encounter was coded as ' 0 ' when at least one of the services required physical presence of the physician and ' 1 ' if physical presence was not required.
COVID pandemic. (See Appendix Table 1 \& Table 2) Each of the services was recoded as a dichotomous measure (0/1). The patient-physician encounters where the physical presence of the physician was required to conduct at least 1 service were deemed as not amenable to telehealth and were coded as ' 0 '. All the encounters where the physical presence of the physician was not required were considered amenable to telehealth and coded as ' 1 '.

We calculated the total number and percentage of physicians and visits in the study sample. We used univariate statistics to examine the number and proportion of physicians who provided e-consults and telephone consults. We also calculated the number and proportion of patient-physician encounters that were amenable to telehealth. Distribution of patient socio-demographic characteristics by telehealth capacity was also examined. We also looked at the distribution of practice characteristics of the physician sample. All data were weighted to obtain nationally representative estimates of the patient-physician interactions and physicians using patient and physician 
weights. We used survey variables to account for the complex NAMCS survey designs.

The current study was approved by the Institution Review Board, American Academy of Family Medicine.

\section{Results}

There were 677 physicians (weighted $n=330,605$ ) in the 2016 and 13,615 patient-physician encounters (weighted $\mathrm{n}=883,725,178$ ) in the NAMCS 2016. Of the total physicians $41 \%$ were primary care and 59\% subspecialists. Greater proportion of physician practices were in MSA than non-MSA (unweighted $93.4 \%$ vs $6.6 \%$ ), were owned by physicians or physician group (unweighted $74.7 \%$ ) and located in the South (40.2\%) (Appendix Table 3).

Nearly $30 \%$ of visits in patients 65 years and older were telehealth amenable compared with $42 \%$ in patients aged 18 to 34 years. (Table 1) A third of the patient-physician encounters related to hypertension $(31 \%$ vs $69.0 \%, P<.021)$ and almost a quarter of the visits to coronary artery disease $(24.7 \%$ vs $75.3 \%, P<.010)$ were amenable to telehealth. About $45 \%$ of the visits for depression were amenable to telehealth (44.9\% vs $55.1 \%, P<.001)$.

Among all physicians in the 2016 analysis sample, $44 \%$ reported making a telehealth encounter, $16 \%$ made e-consults and $42 \%$ telephone consults. (Figure 1) Of the primary care physicians in the 2016 sample, $47 \%$ made any telehealth encounter, $19 \%$ provided e-consults, and $44 \%$ provided telephone consults. In total, of the 850 million patientphysician office-based encounters (all specialties), $35 \%$ were amenable to telehealth using the guidelines outlined above. Among all the patient-physician interactions in ambulatory primary care

Table 3. Proportion of Services Amenable to Telehealth

\begin{tabular}{|c|c|c|c|c|}
\hline \multirow{2}{*}{$\begin{array}{l}\text { Telehealth } \\
\text { Amenable } \\
\text { Services }\end{array}$} & \multicolumn{2}{|c|}{ All Office-Based Visits } & \multicolumn{2}{|c|}{ Primary Care Visits } \\
\hline & $\mathrm{n}$ & $\%$ & $\mathrm{n}$ & $\%$ \\
\hline Yes & $208,347,001$ & 70 & $120,922,770$ & 73 \\
\hline No & $91,000,452$ & 30 & $44,411,214$ & 27 \\
\hline Total & $299,347,453$ & & $165,333,984$ & \\
\hline
\end{tabular}

Source: Author's analysis of the 2016 National Survey of Ambulatory Medical Care Survey weighted by patient weight.

*Telehealth amenable services means all services rendered at a given visit can be delivered via telehealth. settings ( $\mathrm{n}=394$ million), $42 \%$ were amenable to telehealth. (Table 2). Of all the office-based visits, $70 \%$ of services rendered at the visit were telehealth amenable (Table 3), as were $73 \%$ of services provided by primary care physicians.

\section{Discussion}

This study estimates the capacity of primary care to provide telehealth services for COVID-19 related illness, and several other acute and chronic medical conditions.

By our estimates, before COVID-19, 41\% of physicians and $47 \%$ of primary care physicians report using some sort of telehealth in their office, with telephone encounters being the most frequently cited type of telehealth visit. While many primary care physicians report the capacity to provide telehealth, few of the visits coded in NAMCS were delivered via telehealth. We found that a number of services provided $(73 \%)$ and a smaller but significant number of encounters $(42 \%)$ could have been delivered via telehealth.

The predominant form of telehealth provided in our sample was via telephone. This makes sense given that the telephone is available in $100 \%$ of practices and nearly $100 \%$ of patient homes. ${ }^{21}$ Yet, telephone only visits are reimbursable by some payers, they are currently reimbursed at a fraction of the rate of video visits. This has grave financial implications for practices without the infrastructure to support video visits or those that serve patient populations without access to broadband, smartphones or computers.

There is substantial evidence that medically underserved populations, particularly in rural communities, have a lower likelihood of having access to the technology needed to sustain video virtual visits. $^{22}$ Previous studies cited multitude of reasons for demographic disparities in telehealth use including mistrust in use of technology for obtaining care, poor health or technology literacy in seeking health care. ${ }^{23,24}$ A Kaiser Permanente survey demonstrated fewer older and minority patients owned digital devices and had lower ability or were less willing to use internet or email. ${ }^{25}$ Likewise our study also shows patients aged 65 or more and those with chronic conditions less likely to engage in telehealth, which underscores the importance of patient education and training in promoting the use of telehealth services in these subpopulations. 
Figure 1. Proportion of primary care physicians making a given type of encounter (weighted) (NAMCS 2016).

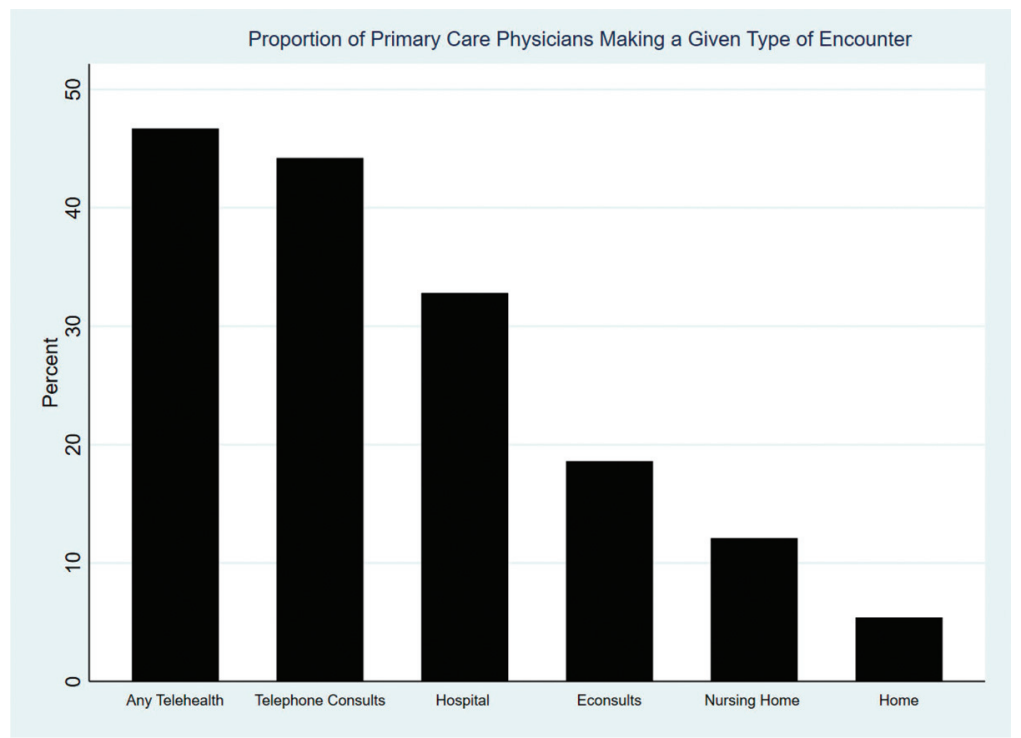

Source: Author's analysis of the 2016 National Ambulatory Medical Survey $(\mathrm{N}=132,500)$ weighted by physician weights

Without either a change to value-based payments or much higher reimbursement rates for telephone visits, we may end up disproportionately adversely affecting practices that support patients with the highest medical and social needs.

This study highlights the need to understand how and where primary care might be delivered. With the advances in virtual care available through telephone, smart phone, desk top cameras, and text, e-mail, and patient portals it is essential to understand the benefits and risks to these care options. While synchronous communication via in-person, face-to-face encounters has been the dominant model, other opportunities for communication have been developed, but under deployed. Meaningful medical encounters may be provided by other synchronous communication through video and audio-only methods. Asynchronous communication may also be a robust method for delivering primary care. Symptom review, feedback, prescription refills, chronic disease management, education, and counseling may all be done via email, text, and other asynchronous methods. It is crucial to provide funding to all forms of quality patient interaction and service provision. The COVID-19 pandemic has led to a realization that some important elements of primary care can be delivered by a patient's local primary care clinician using a host of virtual telehealth methods.
The activities included as amenable to telehealth are a group of general activities included in the NAMCS data collection. As such, they are not specific, diagnosis-related, and do not include a variety of other clinical activities that might be conducted by telehealth. Because NAMCS includes just a small set of general activities, not every encounter with a specific service would be amenable to a virtual visit. For example, while there is evidence that many dermatologic conditions can be amenable to telehealth, ${ }^{10}$ not all dermatologic conditions could be fully managed without a skin scraping or direct treatment. While some visits would not require a patient to be physically in the office, the visit may necessitate the patient travel to another site for lab or imaging. This could be a virtual visit combined with a potential need for lab tests, therefore amenable to telehealth. Emerging digital devices such as home blood pressure machines, home spirometers, and pulse oximetry may provide additional care that can be provided without an in-person visit. However, many of these newer devices are not widely available and represent an area of research and evaluation. We recognize that our estimates may be conservative given the lack of a standard definition of telehealth. Nevertheless, these data provide an important glimpse into the potential to expand telehealth for many common acute and chronic conditions. 


\section{Study Limitations}

NAMCS is a survey of physicians and is therefore subject to bias of the respondents, although, this bias is minimized by a sophisticated data collection process that allows for validation from multiple sources. In addition, we are estimating telehealth capacity by calculating the number of visits that are amenable to telehealth. We are not commenting on the quality of these visits if done via telehealth or in person. Although there is room for more research on the quality of telehealth visits, much of the current research shows that for those visits that are amenable to telehealth, little to no difference in outcomes between visits done in person via telehealth. ${ }^{10-13,26}$

Physicians who participated in the survey but did not see any patients by telehealth during the reporting period and those who refused to participate in the survey were excluded from the public use data. Therefore, estimates for physicians derived from the encounter data may vary slightly from all officebased physicians. For some items the nonresponse bias exceeded $5 \%$, although NAMCS adjusted for nonresponse bias. Finally, the decision to include a service as potentially amenable to telehealth was made by a small group of primary care physicians supported by peer-reviewed literature. While there may be some disagreement among physicians and patients as to what services can be delivered via telehealth, based on NAMCS data collection methods, the list of services assigned as telehealth amenable is a reasonable approximation of the medical services that might be delivered via telehealth.

Since our study is based on 2016 NAMCS data, it does not include CMS changes in telehealth reimbursement and state legislations made in 2019 that impact telehealth adoption rates among physicians, limiting generalizability of our study findings.

\section{Conclusions}

The current study estimates the telehealth capacity in the United States using a nationally representative data source. We found that $35 \%$ of all visits and $42 \%$ of primary care visits are amenable to any kind of telehealth. Our estimates are higher than the 14\% ambulatory telehealth visits reported by Mehrotra et al. during early weeks of COVID-19 pandemic in the US. ${ }^{27}$ However, authors Mehrotra postulate that $40 \%$ of all the patient visits could be done via telehealth, which is comparable to our study estimates. ${ }^{28}$ Before the COVID-19 pandemic, it would be hard to imagine that nearly half of all visits to a primary care office could be done virtually. Yet, in a matter of weeks, health care providers nationwide have completely redesigned their practices using telehealth to sustain care capacity while maintaining social distancing and protecting patients and providers. This rapid transformation will undoubtedly change how we deliver care in the post-COVID-19 era. And although telehealth will likely not be provided at pandemic-era levels, it is likely to be provided more frequently than before. Successful practice transformation in the coming months may highlight areas in which primary care can more fully integrate telehealth modalities in the future. Whether paid for through traditional fee-forservice payment models or expanded prospective payment models, telehealth services may be a substantial component of primary care now and in the future. Our estimates of the telehealth capacity in the outpatient primary care setting may be by practices as they plan how they will deliver care by payers as they make payment model decisions in the post-COVID-19 environment.

To see this article online, please go to: http://jabfm.org/content/ 34/Supplement/S48.full.

\section{References}

1. Bashshur RL, Howell JD, Krupinski EA, Harms KM, Bashshur N, Doarn CR. The empirical foundations of telemedicine interventions in primary care. Telemed J E Health 2016;22:342-75.

2. Gustafson DH, McTavish FM, Chih MY, et al. A smartphone application to support recovery from alcoholism: a randomized clinical trial. JAMA psychiatry 2014;71:566-72.

3. Matkin W, Ordóñez Mena JM, Hartmann Boyce J. Telephone counselling for smoking cessation. Cochrane Database Syst Rev 2019.

4. Muessig KE, Nekkanti M, Bauermeister J, Bull S, Hightow-Weidman LB. A systematic review of recent smartphone, Internet and Web 2.0 interventions to address the HIV continuum of care. Curr HIV/AIDS Rep 2015;12:173-90.

5. Gielen AC, Bishai DM, Omaki E, et al. Results of an RCT in two pediatric emergency departments to evaluate the efficacy of an m-health educational app on car seat use. Amer J Prev Med 2018;54:746-55.

6. LEngle KL, Mangone ER, Parcesepe AM, Agarwal S, Ippoliti NB. Mobile phone interventions for adolescent sexual and reproductive health: a systematic review. Pediatrics 2016;138:e20160884-e20160884.

7. Richter KP, Shireman TI, Ellerbeck EF. Comparative and cost effectiveness of telemedicine versus telephone counseling for smoking cessation. J Med Internet Res 2015;17:e113. 
8. Batsis JA, Pletcher SN, Stahl JE. Telemedicine and primary care obesity management in rural areasinnovative approach for older adults? BMC Geriatr 2017;17:6.

9. Locke ER, Thomas RM, Woo DM, et al. Using video telehealth to facilitate inhaler training in rural patients with obstructive lung disease. Telemedicine and e-Health 2019;25:230-6.

10. Trettel A, Eissing L, Augustin M. Telemedicine in dermatology: findings and experiences worldwide-a systematic literature review. J Eur Acad Dermatol Venereol 2018;32:215-24.

11. Goode AD, Reeves MM, Eakin EG. Telephonedelivered interventions for physical activity and dietary behavior change: an updated systematic review. Am J Prev Med 2012;42:81-8.

12. Mohr DC, Ho J, Duffecy J, et al. Effect of telephone-administered vs face-to-face cognitive behavioral therapy on adherence to therapy and depression outcomes among primary care patients: a randomized trial. JAMA 2012;307: 2278-85.

13. Appel LJ, Clark JM, Yeh HC, et al. Comparative effectiveness of weight-loss interventions in clinical practice. N Engl J Med 2011;365:1959-68.

14. Portnoy JM, Waller M, De Lurgio S, Dinakar C. Telemedicine is as effective as in-person visits for patients with asthma. Ann Allergy Asthma Immunol 2016;117:241-5.

15. Watzke B, Haller E, Steinmann $M$, et al. Effectiveness and cost-effectiveness of telephonebased cognitive-behavioural therapy in primary care: study protocol of TIDe-telephone intervention for depression. BMC Psychiatry 2017;17: 263.

16. Pinnock H, McKenzie L, Price D, Sheikh A. Costeffectiveness of telephone or surgery asthma reviews: economic analysis of a randomised controlled trial. Br J Gen Pract 2005;55:119-24.

17. Shepard DS, Daley MC, Neuman MJ, Blaakman AP, McKay JR. Telephone-based continuing care counseling in substance abuse treatment: economic analysis of a randomized trial. Drug Alcohol Depend 2016;159:109-16.

18. Mehrotra A, Ray K, Brockmeyer DM, Barnett ML, Bender JA. Rapidly converting to "virtual practices": outpatient care in the era of Covid-19. N Engl J Med Catalyst 2020;1.
19. National Center for Health Statistics. NAMCS Micro-File data documentation. Available at: $\mathrm{ftp} / / /$ ftp.cdc.gov/pub/Health_Statistics/NCHS/Dataset_ Documentation/NAMCS $\backslash 2016$. Accessed on March 20, 2020.

20. National Center for Health Statistics. Sample national ambulatory medical care survey 2016 patient record. Available at: https://www.cdc.gov/ nchs/data/ahcd/2016_namcs_prf_sample_card.pdf. Accessed on March 20, 2020.

21. USA Today. Coronavirus: Family physicians provide telehealth care at risk of bankruptcy. Available at: https://www.usatoday.com/story/opinion/2020/04/07/ coronavirus-family-physicians-provide-telehealth-carerisk-bankruptcy-column/2942535001/. Accessed on April 13, 2020.

22. Federal Communications Commission. Mapping broadband health in America. Available at: https:// www.fcc.gov/health/maps. Accessed on March 28, 2020.

23. Nouri SS, Avila-Garcia P, Cemballi AG, Sarkar U, Aguilera A, Lyles CR. Assessing mobile phone digital literacy and engagement in user-centered design in a diverse, safety-net population: mixed methods study. JMIR Mhealth Uhealth 2019;7:e14250.

24. Nouri S, Khoong EC, Lyles CR, Karliner L. Addressing equity in telemedicine for chronic disease management during the Covid-19 pandemic. catalyst non-issue content. N Engl J Med Catalyst 2020;1.

25. Gordon NP, Hornbrook MC. Differences in access to and preferences for using patient portals and other eHealth technologies based on race, ethnicity, and age: a database and survey study of seniors in a large health plan. J Med Internet Res 2016;18:e50.

26. McKellar J, Wagner T, Harris A, Oehlert M, Buckley S, Moos R. One-year outcomes of telephone case monitoring for patients with substance use disorder. Addict Behav 2012;37:1069-74.

27. Mehrotra A, Chernew M, Linetsky D, Hatch H, Cutler D. The impact of the COVID-19 pandemic on outpatient visits: a rebound emerges. The Commonwealth Fund. 2020. Available at: https:// www.commonwealthfund.org/publications/2020/apr/ impact-covid-19-outpatient-visits. Accessed July 20, 2020.

28. Rubin R. COVID-19's crushing effects on medical practices, some of which might not survive. JAMA 2020;324:321. 


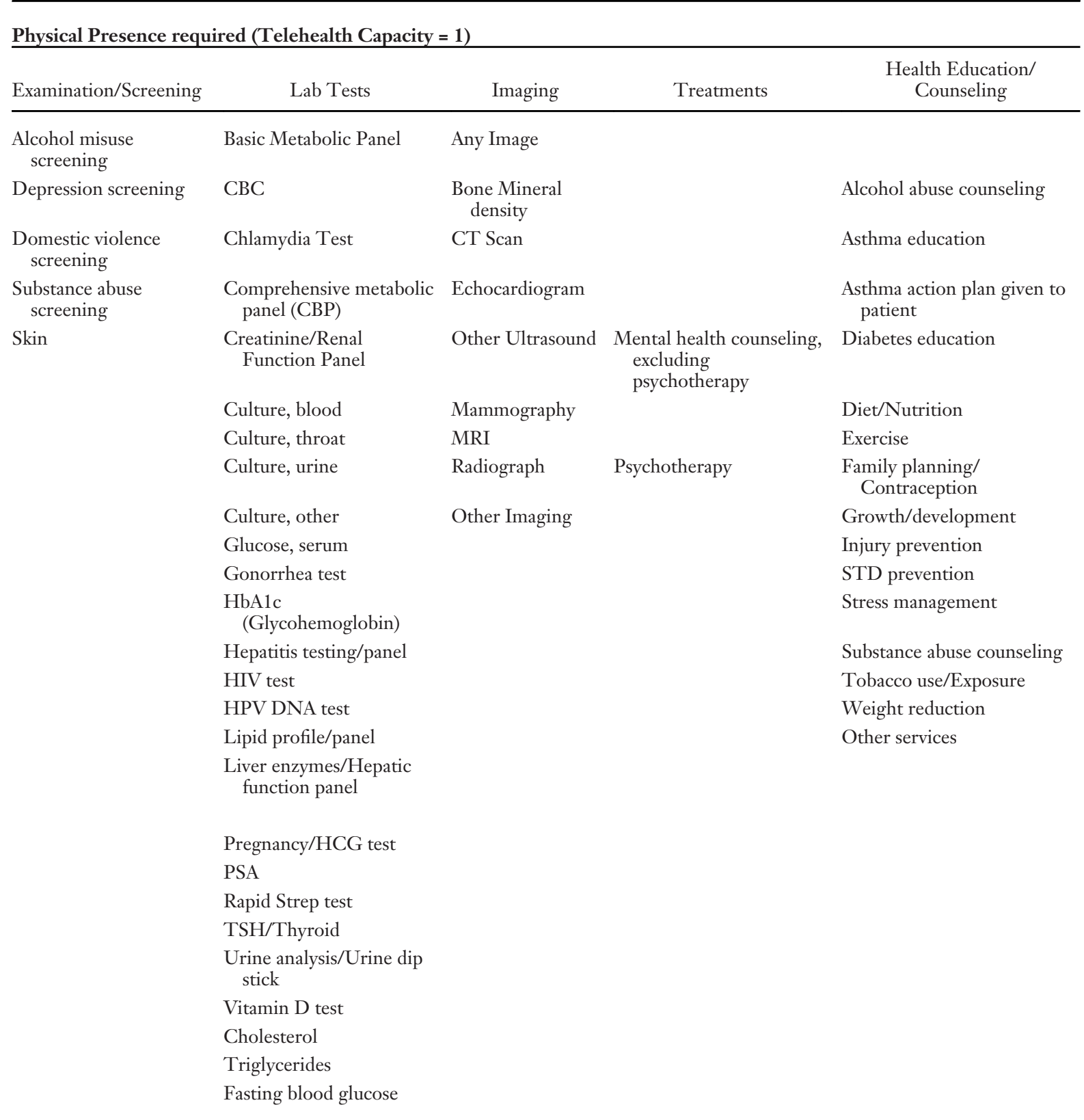

$\underline{\text { Physical Presence required (Telehealth Capacity }=0 \text { ) }}$

\begin{tabular}{llll}
$\begin{array}{l}\text { Examination/ } \\
\text { Screening }\end{array}$ & Procedures & $\begin{array}{l}\text { Lab } \\
\text { Tests }\end{array}$ & Treatments \\
\hline $\begin{array}{l}\text { Breast Exam } \\
\text { Foot Exam }\end{array}$ & $\begin{array}{l}\text { Audiometry } \\
\text { Biopsy provided }\end{array}$ & Pap test & $\begin{array}{l}\text { Cast/splint/wrap } \\
\text { Complementary and alternative medicine } \\
\text { (CAM) }\end{array}$ \\
\hline
\end{tabular}




\begin{tabular}{|c|c|c|c|}
\hline $\begin{array}{l}\text { Examination/ } \\
\text { Screening }\end{array}$ & Procedures & $\begin{array}{l}\text { Lab } \\
\text { Tests }\end{array}$ & Treatments \\
\hline Neurologic & Cardiac stress test & & Durable medical equipment \\
\hline Pelvic & Colonoscopy & & Home health care \\
\hline Rectal & $\begin{array}{l}\text { Cryosurgery(cryotherapy)/destruction of } \\
\text { tissue }\end{array}$ & & \\
\hline \multirow[t]{11}{*}{ Retinal } & EKG/ECG & & Occupational therapy \\
\hline & Electroencephalogram (EEG) & & Physical therapy \\
\hline & Electromyogram (EMG) & & \\
\hline & Excision of tissue provided & & Radiation therapy \\
\hline & Fetal monitoring & & Wound care \\
\hline & Peak flow & & \\
\hline & Sigmoidoscopy provided & & \\
\hline & Spirometry & & \\
\hline & Tonometry & & \\
\hline & Tuberculosis skin testing (PPD) & & \\
\hline & $\begin{array}{l}\text { Upper gastrointestinal endoscopy/EGD } \\
\text { provided }\end{array}$ & & \\
\hline
\end{tabular}

CBC, Complete blood count; HPV, human papillomavirus; HCG, human chorionic gonadotrophin; HIV, human immunodeficiency virus; TSH, thyroid-stimulating hormone; MRI, magnetic resonance imaging; STD, sexually transmitted disease; EKG/ECG, electrocardiogram; PPD, purified protein derivative (TB test); EGD, esophagogastroduodenoscopy. 







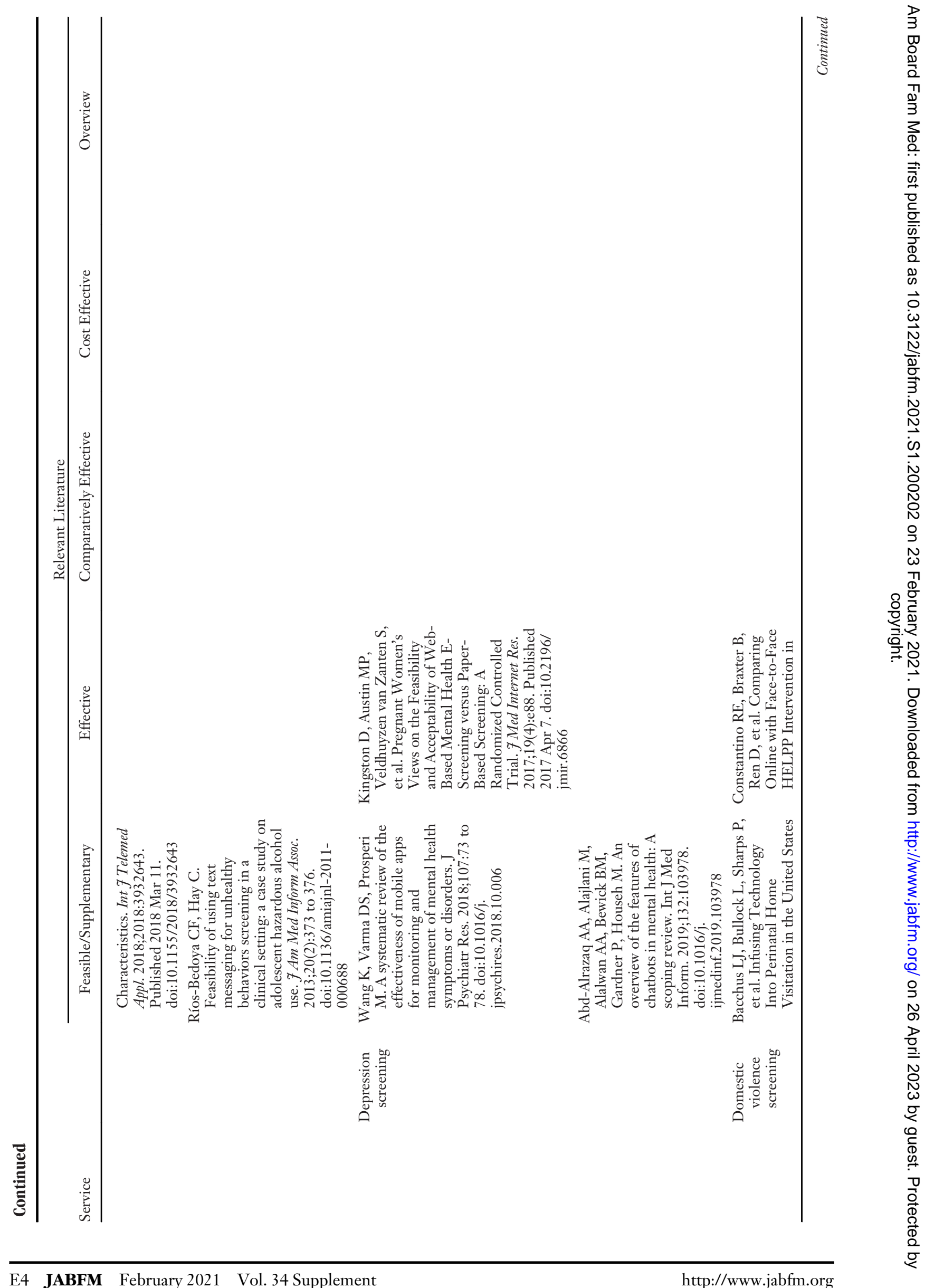




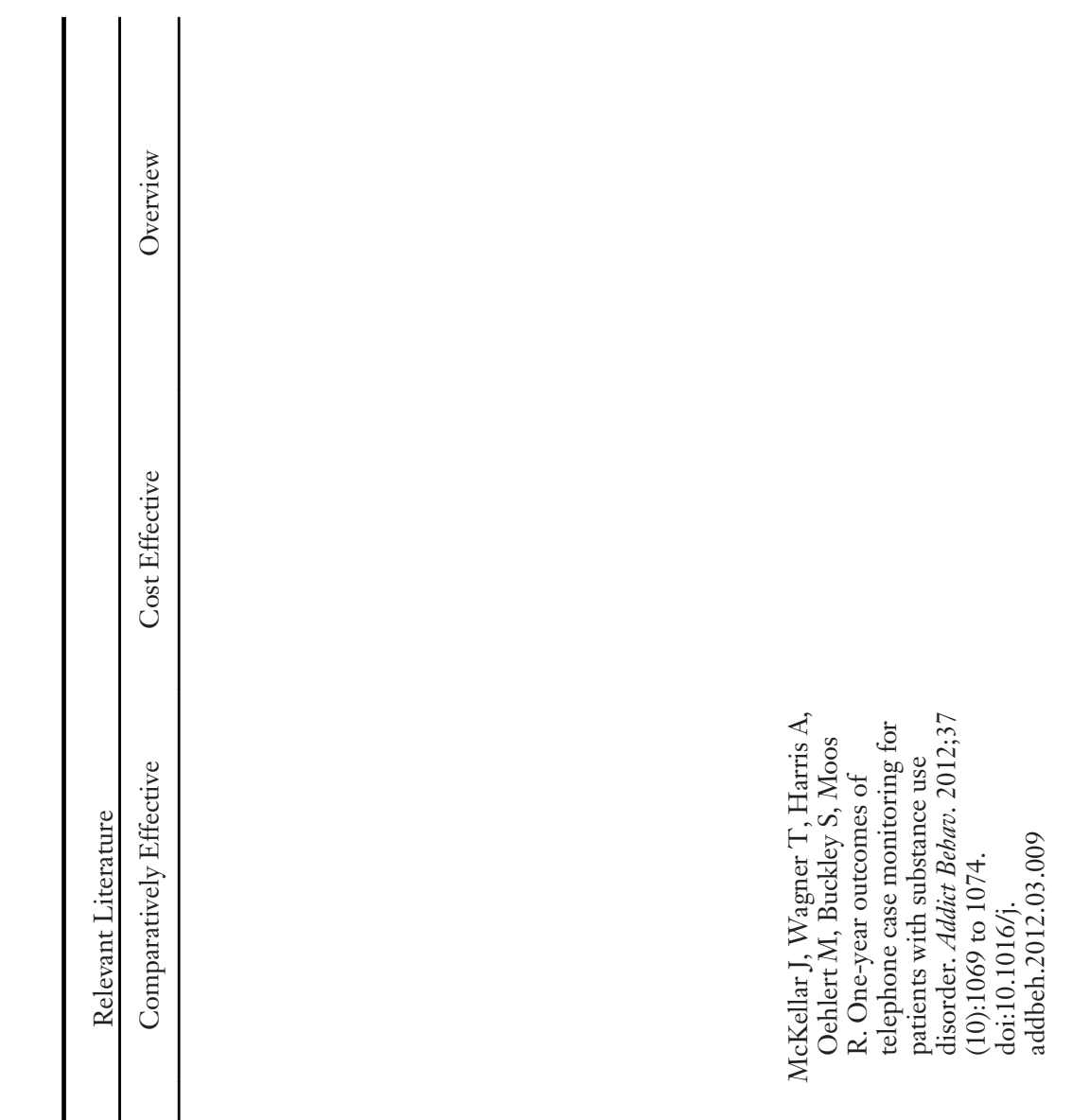

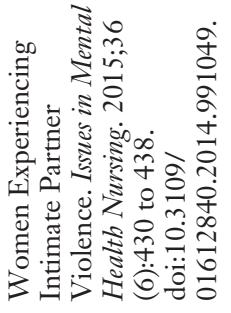
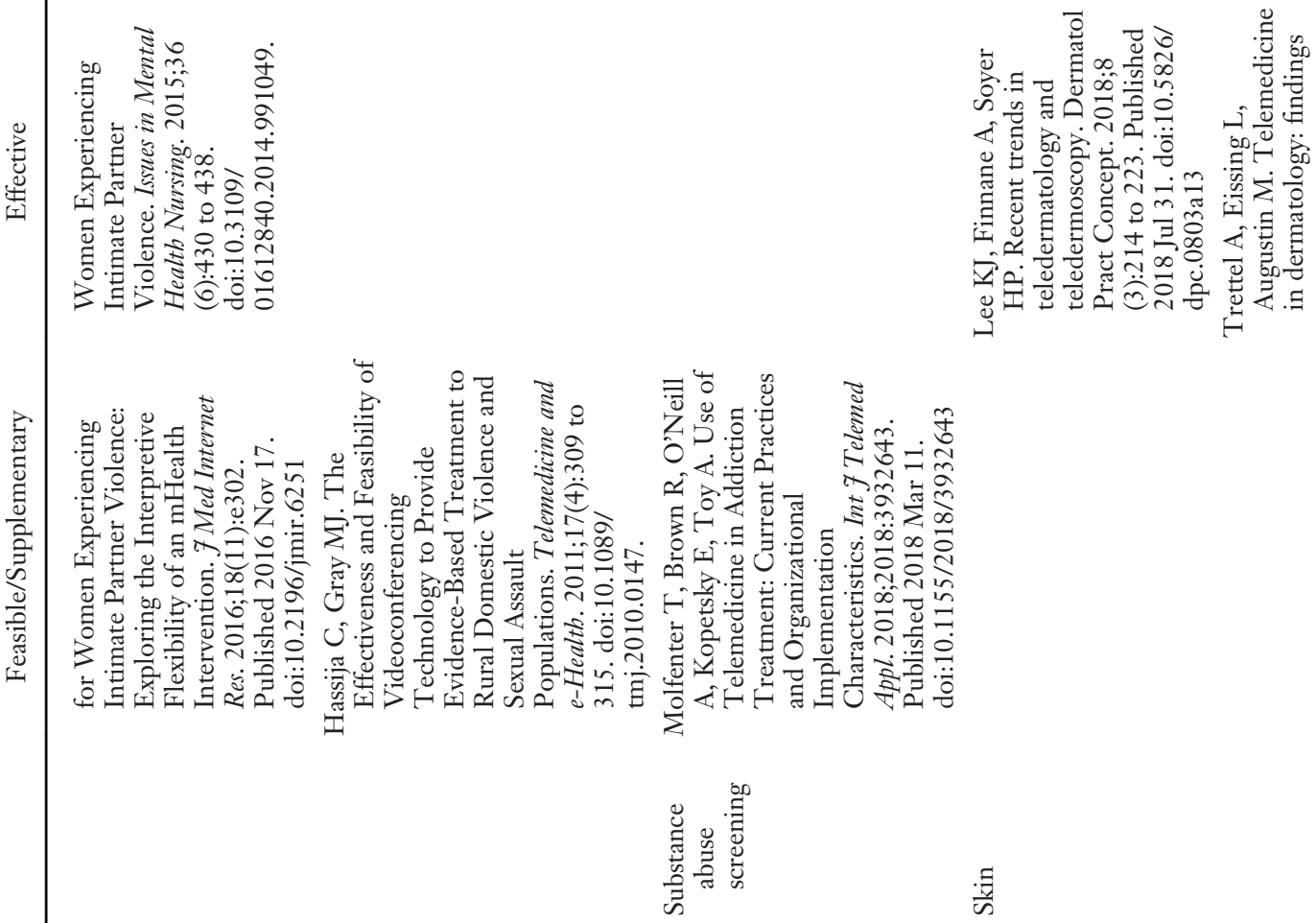


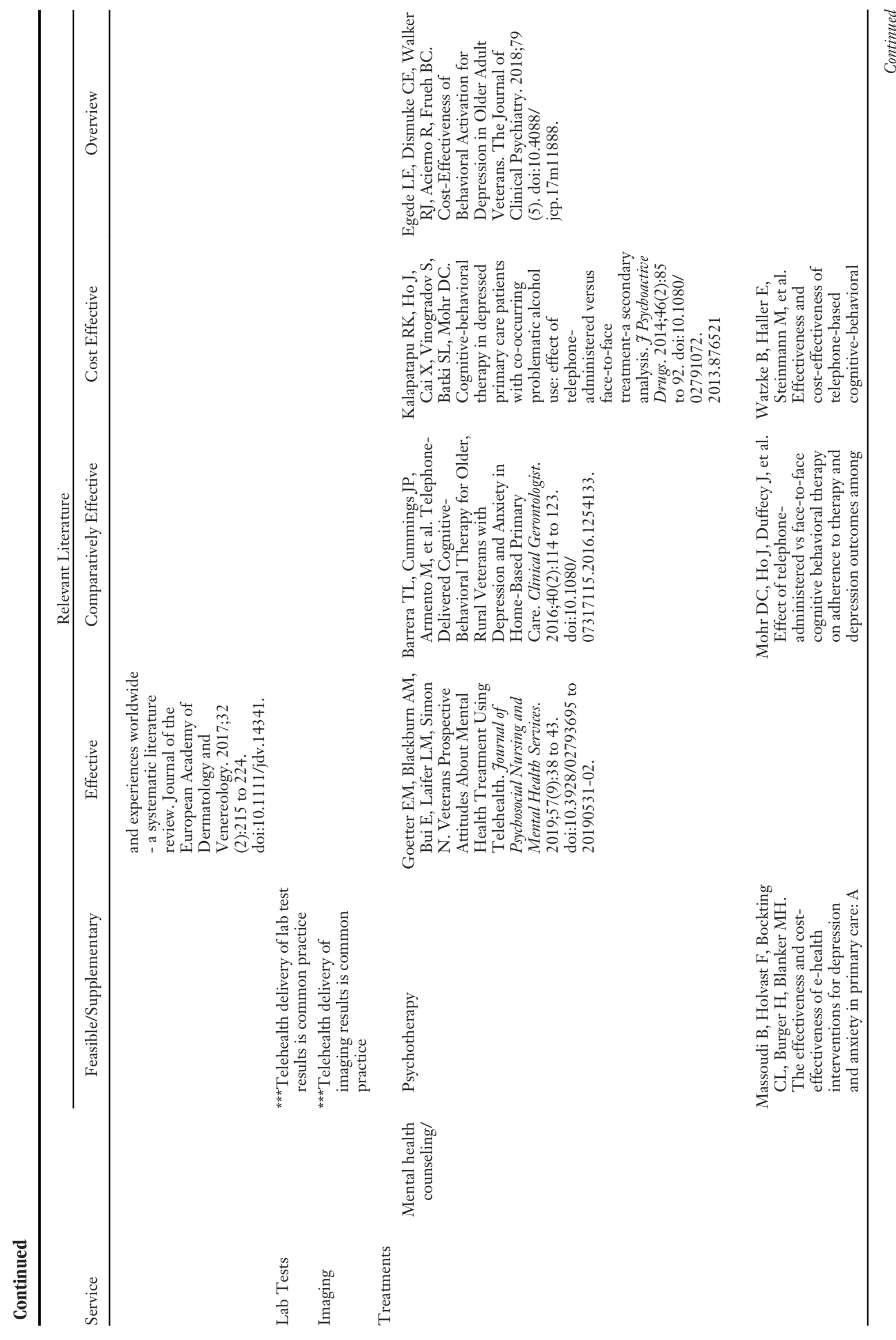




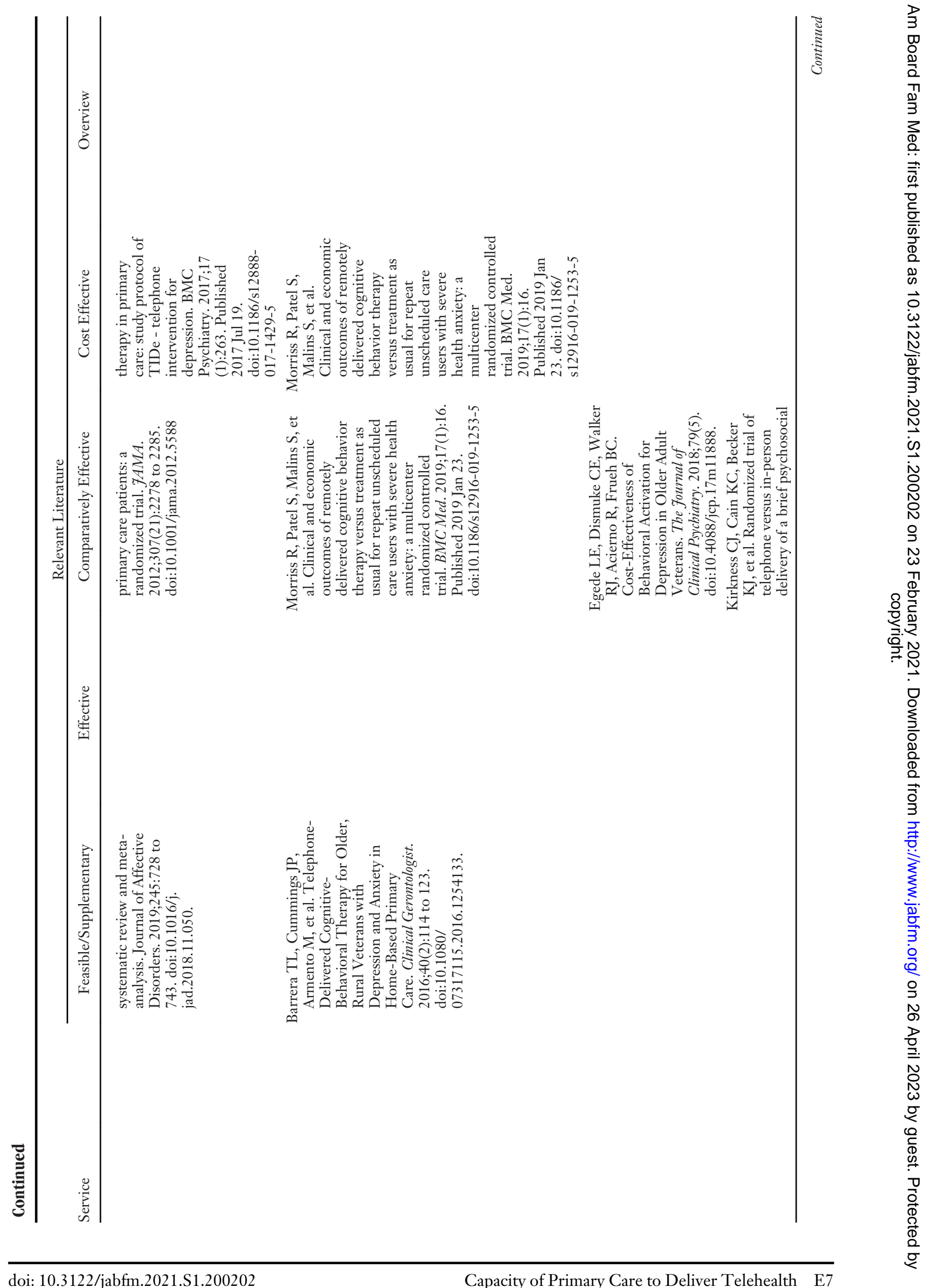





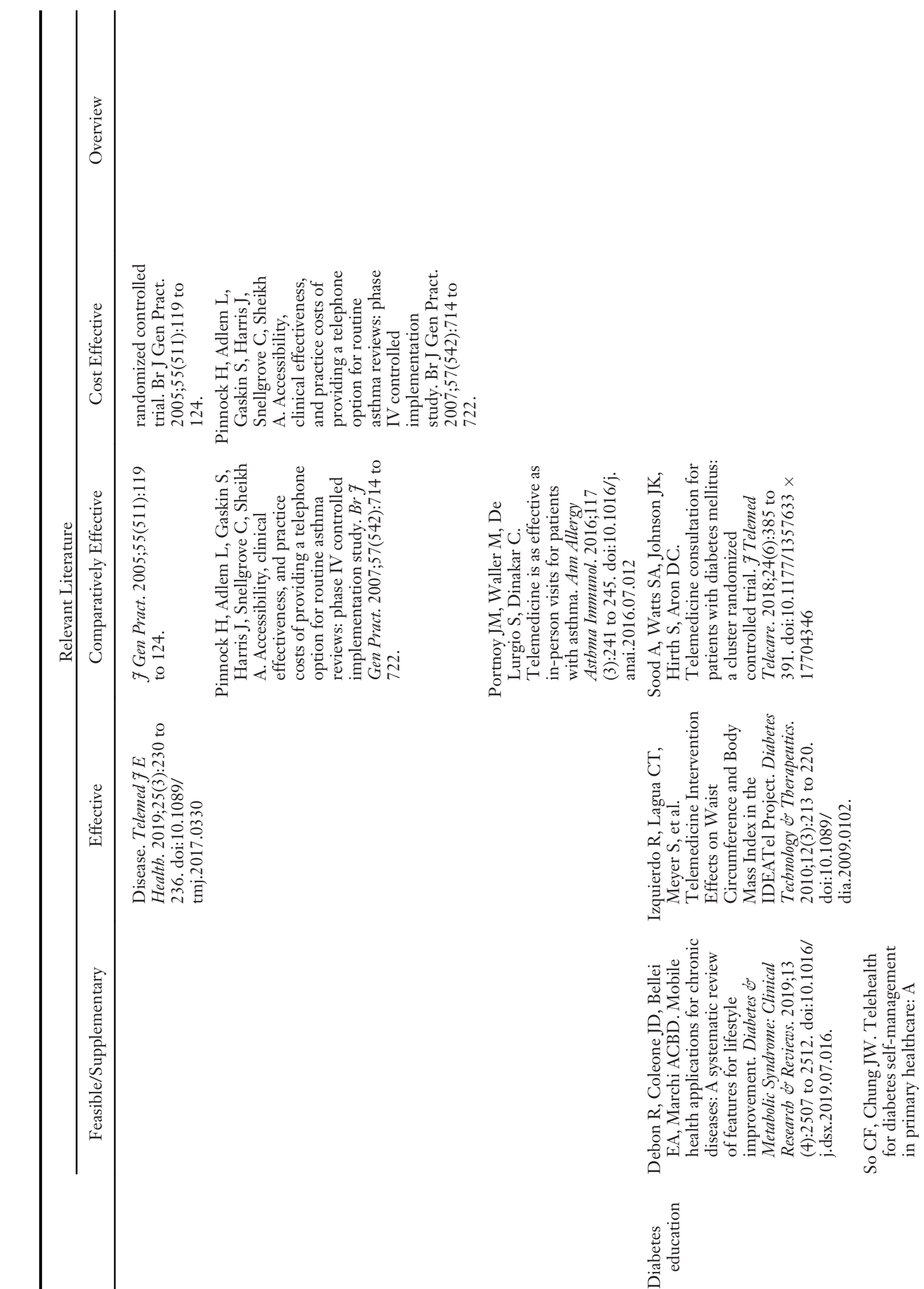

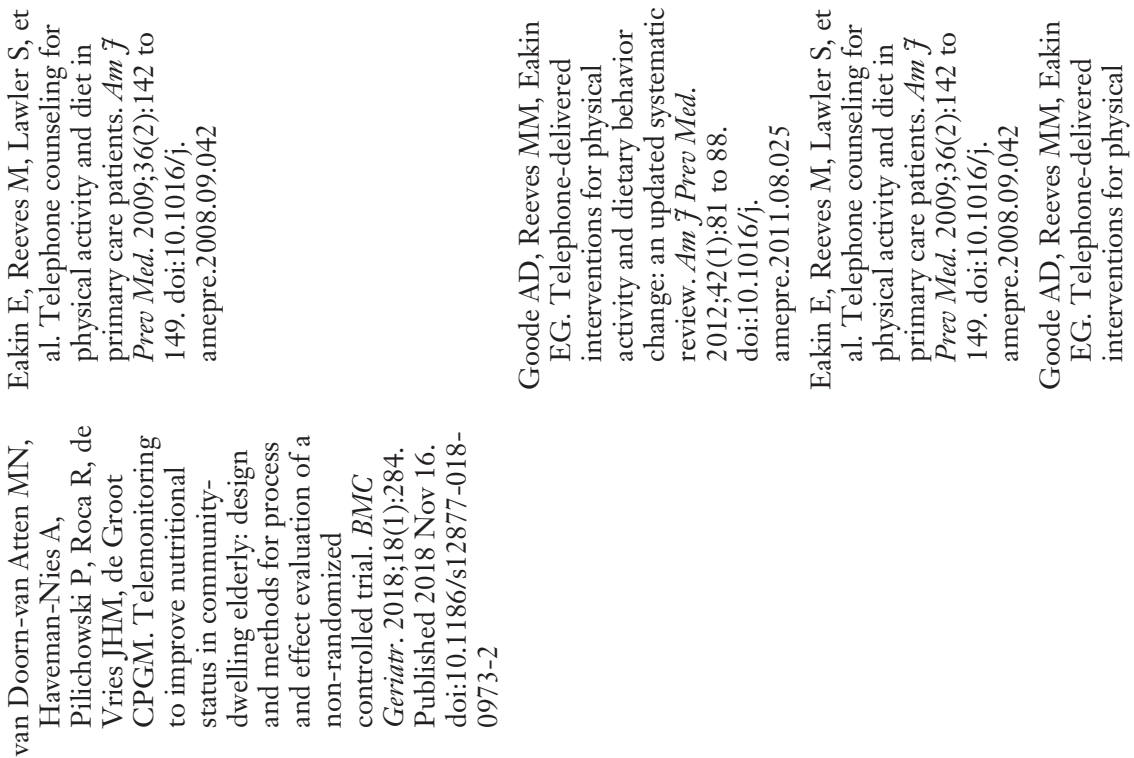

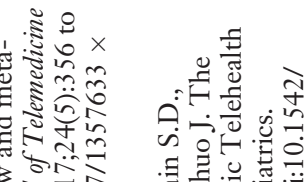

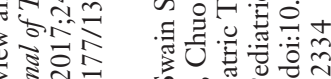

ए

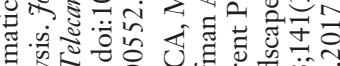

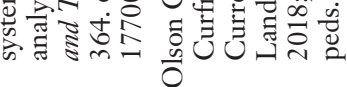

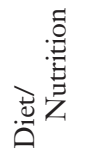



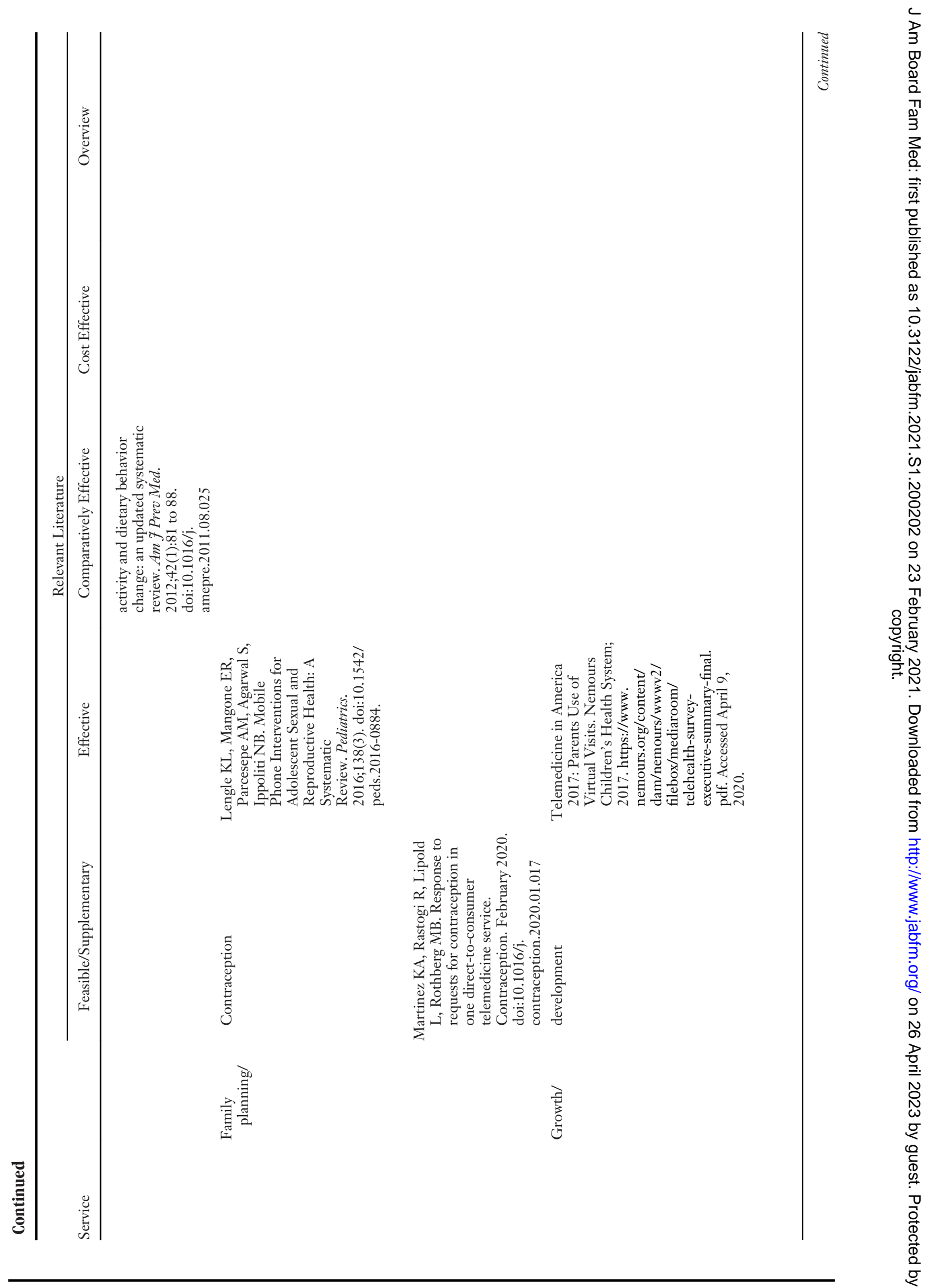


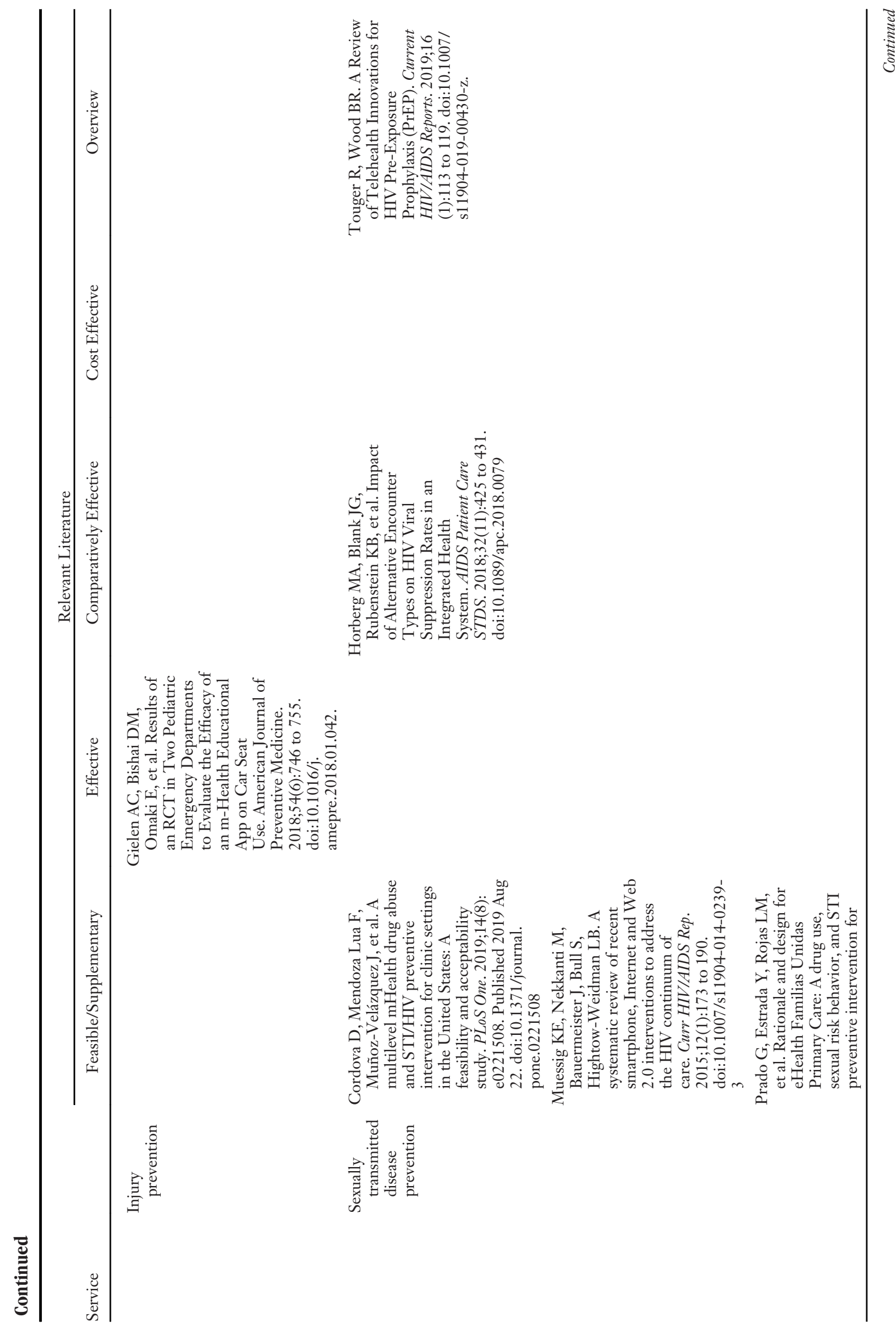



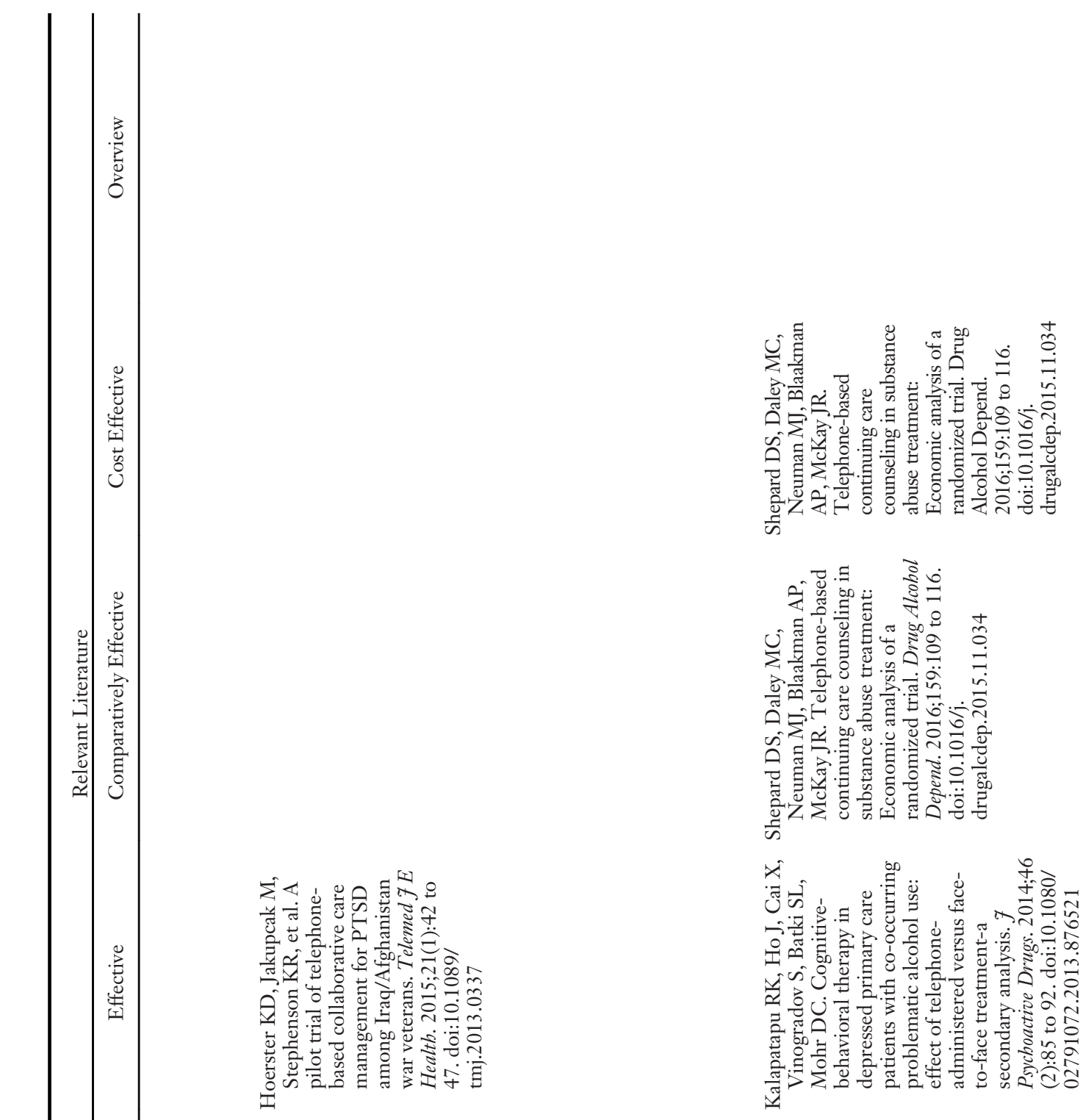

苂亡
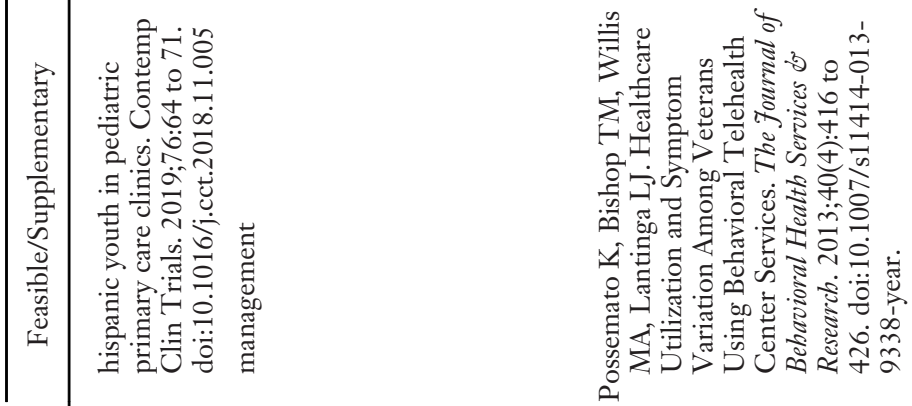

की

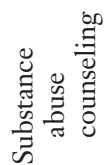




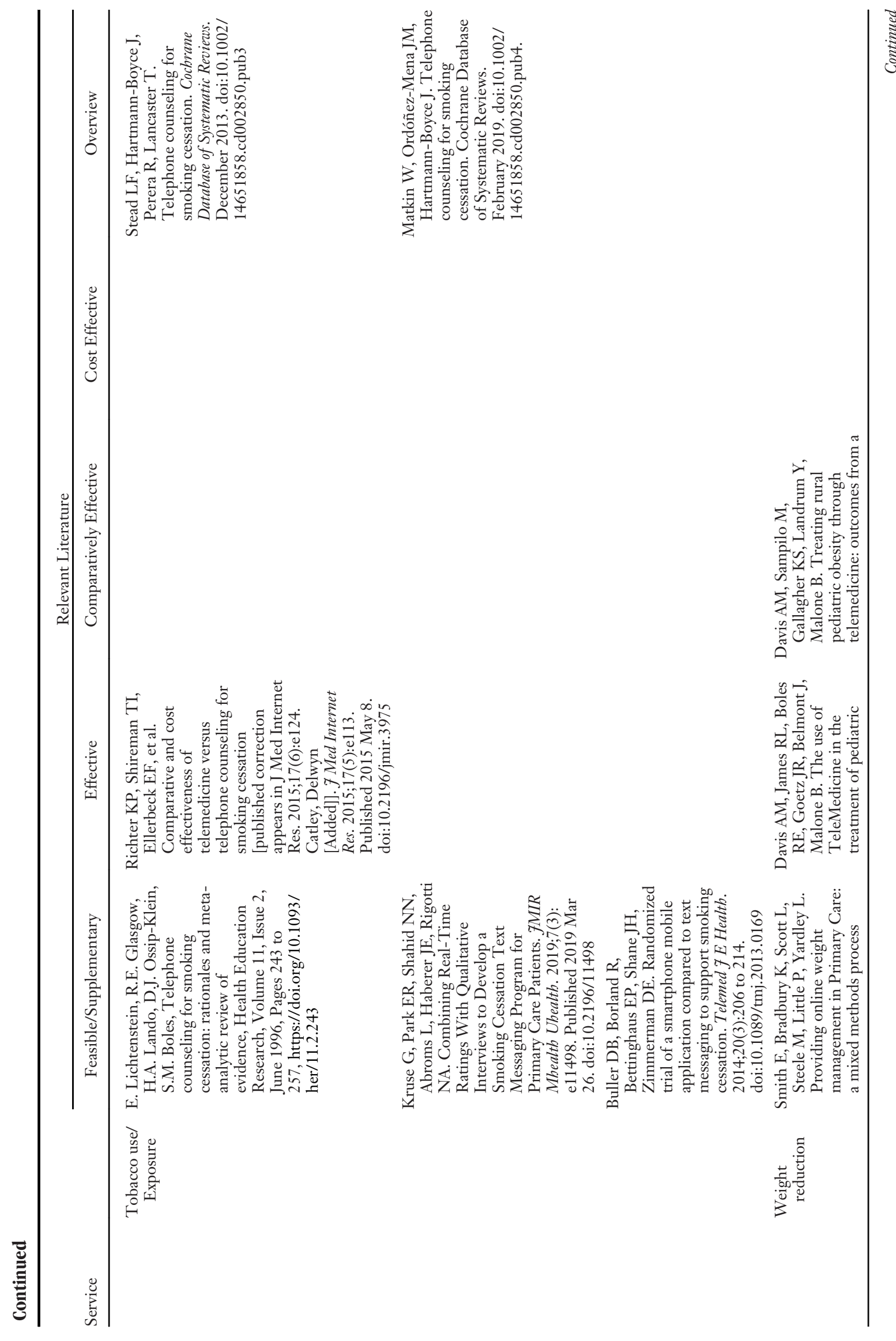




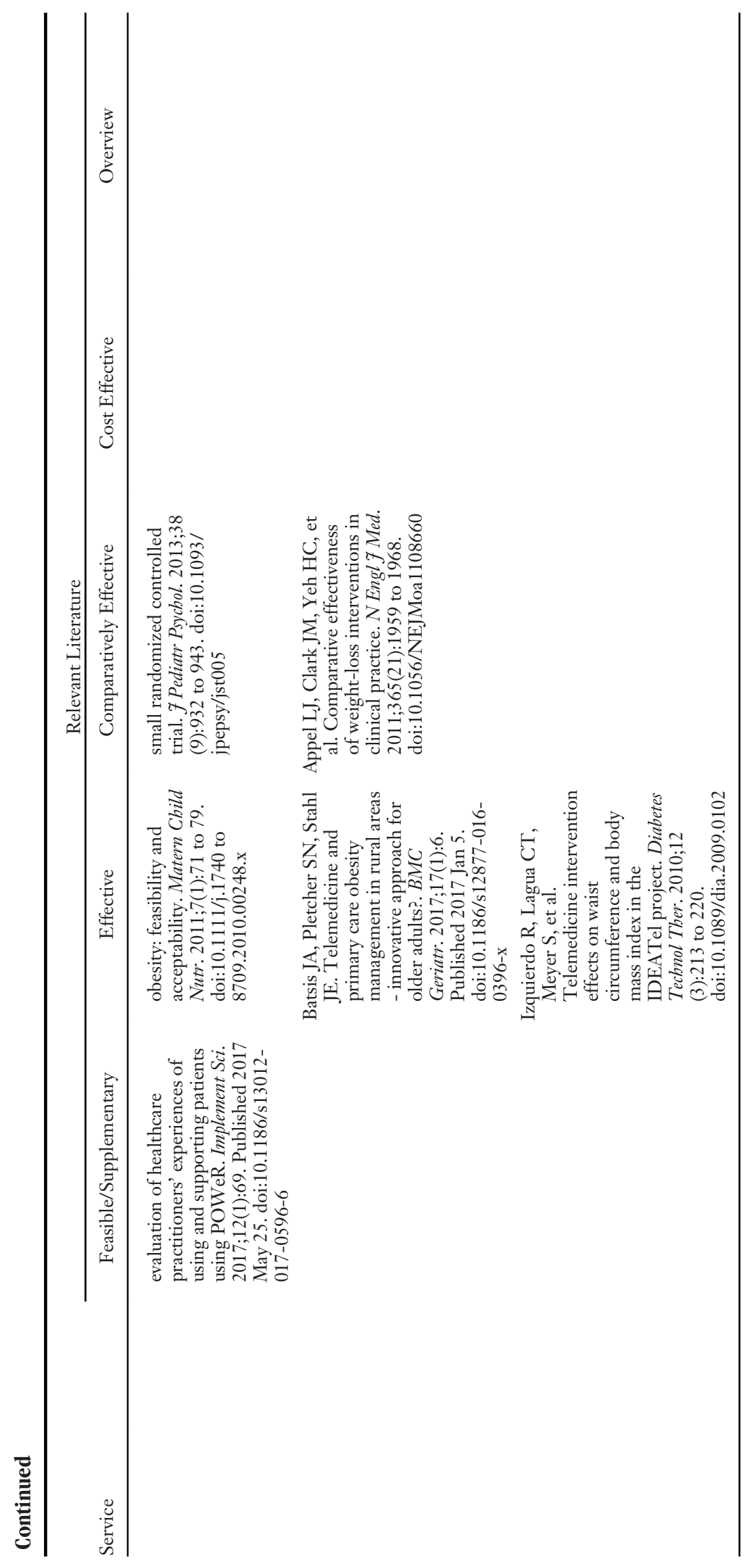


Appendix 3. Distribution of Patient-Physician Encounters by Physician Practice Characteristics (NAMCS 2016)

\begin{tabular}{|c|c|c|c|c|c|}
\hline & & \multicolumn{2}{|c|}{ Unweighted } & \multicolumn{2}{|c|}{ Weighted } \\
\hline & & $\mathrm{n}$ & $\%$ & $\mathrm{n}$ & $\%$ \\
\hline \multirow[t]{2}{*}{ Metropolitan Statistical Area } & MSA & 623 & 93.4 & 306508 & 92.7 \\
\hline & Non-MSA & 54 & 6.6 & 24097 & 7.3 \\
\hline \multicolumn{6}{|l|}{ Region of practice location } \\
\hline & Northeast & 142 & 25.4 & 66666 & 20.2 \\
\hline & Midwest & 146 & 17.9 & 70946 & 21.5 \\
\hline & South & 255 & 40.2 & 108595 & 32.9 \\
\hline & West & 134 & 16.5 & 84398 & 25.5 \\
\hline \multicolumn{6}{|l|}{ Practice Ownership } \\
\hline & Physician or physician group & 519 & 74.7 & 242,058 & 73.2 \\
\hline & Medical/academic health center; Community health center & 61 & 10.5 & 33,115 & 10.0 \\
\hline & Insurance company, health plan, or HMO; & 62 & 9.2 & 38,109 & 11.5 \\
\hline & Unknown & 35 & 5.7 & 17323 & 5.3 \\
\hline & & 677 & 100.0 & 330,605 & 100.0 \\
\hline
\end{tabular}

Source: Author's Analysis of the 2016 National Survey of Ambulatory Medical Care Survey weighted by physician weight. (n $=677$ equivalent to 330,605 nationally representative sample of physicians).

MSA, Metropolitan statistical area; HMO, Health maintenance organization. 